\title{
(Des)acolhimento institucional de crianças e adolescentes: aspectos familiares associados
}

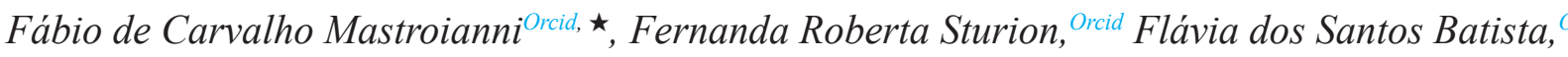 \\ Karen Cristina Amaro, ${ }^{\text {Orcid Talita Bombarda Ruim }}{ }^{\text {Orcid }}$ \\ Universidade de Araraquara, São Paulo, SP, Brasil
}

Resumo

\begin{abstract}
A história tem revelado a necessidade de proteger crianças e adolescentes em situação de risco, tornando-se imperativo atentar-se às condições de desenvolvimento da infância. Buscou-se analisar as informações processuais relacionadas ao acolhimento institucional destes sujeitos, identificando quais aspectos relacionados à dinâmica familiar podem contribuir para o acolhimento elou o desacolhimento. Utilizou-se o método de pesquisa documental e análise de conteúdo; observou-se que o uso de álcool elou drogas pelos responsáveis é um dos principais fatores associados ao acolhimento $(90,2 \%)$, podendo estar associado a outros motivos, tais como negligência dos pais no exercício da função parental (68,3\%) e dos cuidados básicos (36,6\%). Contudo, a frequência de contato e a regularidade da família com as crianças e adolescentes durante o periodo de acolhimento pode favorecer a reintegração. Conclui-se que investir em políticas públicas que fortaleçam os vínculos familiares e o protagonismo social se mostra fundamental para garantir o direito à convivência familiar.
\end{abstract}

Palavras-chave: acolhimento institucional; infância; adolescência; pesquisa documental; análise de conteúdo.

\section{Admission or egress of children and adolescents in shelters: family aspects}

\begin{abstract}
The history has revealed the need to protect children and adolescent at risk, becoming imperative the attention on the conditions of childhood development. We analyzed procedural information related to institutional care of these subjects, by identifying the aspects associated with the familiar dynamic that may contribute to the admission or egress in shelters. We used both documentary research and content analysis research methods; the alcohol and/or drug use by the responsible for the children and adolescents is one of the main factors that lead to institutional care (90.2\%), among other reasons, as parent negligence at parental role (68.3\%) and at basic care (36.6\%). Notwithstanding, the frequency and the regularity on the contact of the family to the children and adolescent during the shelter period can promote the reintegration. It was possible to conclude that investments on public politics, which strengthen the family bonds and the social involvement, are essential to assure the rights to a family life.
\end{abstract}

Keywords: institutional care; childhood; adolescence; documentary research; content analysis.

\section{Introdução}

A relação entre crianças e adolescentes em situação de risco com os adultos e as instituições responsáveis por estas demandas passou, ao longo da história, por diversas transformações. No Brasil imperial, indivíduos nessas condições recebiam tratamento jurídico semelhante àqueles aplicados aos adultos através do código penal vigente, onde invariavelmente os conflitos eram resolvidos por meio da privação de liberdade (MIRANDA, 2017). O Estado não considerava sua condição peculiar e a importância dada aos seus interesses, como educação e assistência, eram realizadas pelas organizações filantrópicas e ordens religiosas, através das Santas Casas de Misericórdia (CUNHA; BOARINI, 2010).

A instituição do primeiro código voltado a esta população (Código de Menores [BRASIL, 1927]) surgiu neste contexto social de medidas repressivas (doutrina penal). A principal mudança trazida com aquela legislação foi a substituição da aplicação de penas por medidas de prevenção criminal e assistência, através das internações (MIRANDA, 2017). Um pouco mais de meio século após, este código foi alterado pela Lei $\mathrm{n}^{\mathrm{0}} 6.697$ $(\text { BRASIL, 1979) })^{1}$ que, embora revogasse a lei anterior, ^Endereço para correspondência: Universidade de Araraquara. Rua Carlos Gomes, 1338, Centro, Araraquara, SP - Brasil. CEP: 14801-340. E-mail: psicomastroianni@gmail.com, fersturion@hotmail.com, psicologia.flaviabatista@gmail. com,karen.amaro@hotmail.com, talitabombarda@yahoo.com

'Substituída pela Lei no ${ }^{\circ} 8.069$ (BRASIL, 1990). manteve fundamentos comuns. Baseada na doutrina da situação irregular, o novo Código de Menores (BRASIL, 1979) não fazia distinção quanto ao "menor" considerado "delinquente" (que havia cometido um crime qualificado) daquele em situação de abandono ou de dificuldade (AYRES; CARDOSO; PEREIRA, 2009).

Apesar dos avanços, o código ainda fomentava a distinção entre infância (aqueles incluídos na cobertura das políticas públicas e sob a proteção de suas famílias) e menoridade: crianças e adolescentes excluídos das políticas públicas básicas (AYRES; CARDOSO; PEREIRA, 2009). A responsabilidade sobre estes indivíduos era atribuída somente às famílias e como o Estado não tinha a obrigação de proteger a família por meio de programas sociais, agia apenas quando estivessem em condição irregular, atuando, entretanto de maneira repressiva (PITTA; FONTOURA, 2009).

Embora algumas legislações já mencionassem a importância da família no desenvolvimento da infância, foi principalmente no final do século XX, por meio de uma nova constituição (BRASIL, 1988) e a criação do Estatuto da Criança e do Adolescente (Lei no 8.069/90) que tal reconhecimento recebeu maior ênfase. O artigo $227^{2}$ da

\footnotetext{
${ }^{2}$ Art. 227. É dever da família, da sociedade e do Estado assegurar à criança, ao adolescente e ao jovem, com absoluta prioridade, o direito à vida, à saúde, à alimentação, à educação, ao lazer, à profissionalização, à cultura, à dignidade, ao respeito, à liberdade e à convivência familiar e comunitária, além de colocá-los a salvo de toda forma de negligência, discriminação,
} 
Constituição Federal e o artigo $4^{\circ}$ do estatuto ${ }^{3}$ ratificaram a prioridade absoluta a crianças e adolescentes, atribuindo não só à família, mas a todos, a responsabilidade sobre o desenvolvimento saudável destes indivíduos. Neste contexto, a família passou a receber ainda mais importância no âmbito de proteção social, devendo o Estado intervir para protegê-la ao invés de substituí-la por meio de medidas repressivas e de internação, como ocorria no código anterior (CUNHA; BOARINI, 2010).

Se o código anterior sustentava a cultura da institucionalização, principalmente da população economicamente desfavorecida, por meio da constituição e do estatuto foi construído um novo paradigma sobre as famílias (MIRANDA, 2017). De julgada, substituída e excluída pelo Estado, a instituição familiar passou a ser considerada como o melhor lugar de acolhimento, proteção e espaço de atenção aos seus membros, devendo permitir aos filhos desenvolver a socialização e a construção de suas subjetividades (VONS; MIRANDA, 2009).

O Estado neste contexto deve auxiliá-la a desenvolver suas potencialidades e ajudá-la a se recuperar, propondo parcerias no resgate e no crescimento da instituição familiar (MOREIRA; MIRANDA, 2007). Neste sentido, as medidas de acolhimento de crianças e adolescentes visando protegê-las tornam-se aplicáveis apenas em situações excepcionais, devendo-se garantir o direito à convivência familiar, de preferência junto à família natural ou através de colocação em família substituta, quando a primeira alternativa não for possível (AYRES; CARDOSO; PEREIRA, 2009).

Apesar do caráter provisório e excepcional na prática ainda se observa a cultura da institucionalização, gerando acolhimentos inadequados e ineficazes. Este quadro se deve ao limitado acesso de algumas famílias às políticas sociais de proteção (VONS; MIRANDA, 2009). A assistência social como política pública de proteção também configura uma situação nova, pois somente com a constituição de 1988 é que passou a se pautar na universalidade da cobertura e do atendimento, integrando o Sistema de Seguridade Social ao lado da Saúde, ambas não contributivas, e da Previdência Social, esta sim contributiva (BRASIL, 2008).

Em 1993 a assistência social foi regulamentada pela LOAS (Lei Orgânica da Assistência Social, Lei no 8.742 [BRASIL, 1993]), criando-se uma nova matriz para a política de assistência social. Esta passa a ser entendida como política de proteção às pessoas, às circunstâncias e dentre elas, o seu principal núcleo de apoio: a família (BRASIL, 2005). O modelo assistencialista, marcado pela ausência de responsabilidade do Estado e por ações circunstanciais é abandonado, levando a partir de 2005 à construção do SUAS (Sistema Único de Assistência Social) (BRASIL, 2005).

\footnotetext{
exploração, violência, crueldade e opressão. Redação dada pela Emenda Constitucional $\mathrm{n}^{\circ} 65$ (BRASIL, 2010).

${ }^{3}$ Art. $4^{\circ}$. É dever da família, da comunidade, da sociedade em geral e do poder público assegurar, com absoluta prioridade, a efetivação dos direitos referentes à vida, à saúde, à alimentação, à educação, ao esporte, ao lazer, à profissionalização, à cultura, à dignidade, ao respeito, à liberdade e à convivência familiar e comunitária (BRASIL, 1990).
}

Para a sua implantação o Conselho Nacional de Assistência Social, após ampla mobilização nacional, editou em 2004 a PNAS (Política Nacional de Assistência Social) a qual prevê entre os seus principais objetivos a construção de serviços, programas, projetos e benefícios de proteção social para famílias, indivíduos e grupos. Estas estratégias visam ampliar o acesso aos bens e serviços socioassistenciais, assegurando que as ações tenham centralidade na família e que garantam a convivência familiar e comunitária (BRASIL, 2008).

Nesta perspectiva as políticas de assistência social passam a se concentrar em intervenções que estimulem maior autonomia, promovendo o desenvolvimento humano e social. Ao invés do assistencialismo incentivado por um Estado tutelador, insere-se o conceito de direito à assistência, no qual o enfoque é sobre o desenvolvimento e a autonomia dos indivíduos e não na dependência dos mais vulneráveis em relação ao Estado (BRASIL, 2008).

No que se refere a crianças e adolescentes, um processo participativo de elaboração conjunta resultou na criação do Plano Nacional de Promoção, Proteção e Defesa do Direito de Crianças e Adolescentes à Convivência Familiar e Comunitária (BRASIL, 2006). Este Plano constitui um marco nas políticas públicas brasileiras, pois visa romper com a cultura da institucionalização, ao fortalecer o paradigma da proteção integral e da preservação dos vínculos familiares e comunitários preconizados pelo estatuto.

Em conjunto com as políticas de assistência social, busca a manutenção dos vínculos familiares e comunitários e está, portanto diretamente relacionada ao investimento nas políticas públicas de atenção à família. Tal iniciativa reconhece a importância da mobilização do Estado e da sociedade para que crianças e adolescentes sejam vistos de forma indissociável de seu contexto familiar e comunitário (BRASIL, 2006).

Destarte, ao se referir ao acolhimento de crianças e adolescentes, o paradigma atual exige que os agentes sociais (profissionais e técnicos envolvidos em serviços e equipamentos de políticas públicas dos estados e dos municípios, junto ao poder judiciário) e a comunidade em geral atuem no sentido de fortalecer e apoiar a instituição familiar (MOREIRA, 2014). O acolhimento pode oferecer proteção material, mas não atende as necessidades afetivas, assim como não oferece espaço de referência e de organização da identidade, assujeitando crianças e adolescentes (RAMOS, 2009).

A dicotomia entre as práticas e a lei se mostra ainda mais acentuada quando se observa que a legislação prevê a aplicação de medidas de proteção direcionadas também aos pais ou responsáveis nas ocasiões em que os filhos estiverem em situação de risco, remetendo, portanto o dever do Estado e da sociedade com a família (BRASIL, 2006). O referido plano e autores como Ayres, Cardoso e Pereira (2009) destacam a importância de se reverter a cultura de institucionalização, alterando a própria dinâmica das instituições de acolhimento que, por operarem

Fractal, Rev. Psicol., v. 30 - n. 2, p. 223-233, 2018 
através de uma dinâmica assistencialista, geralmente não favorecem o protagonismo social das famílias, estigmatizando-as e culpando-as pelas dificuldades que possuem.

Para Moreira e Miranda (2007) seria reducionista culpar as famílias ou atribuir apenas aos pais a responsabilidade do problema, deixando-se de observar que muitas das condições de vulnerabilidade transcendem a geração dos genitores e acumulam falhas de contínuas políticas de exclusão e de desigualdade social que fazem parte da história do Brasil. Uma rede de proteção mais integrada e articulada com a comunidade e as instituições, sejam elas governamentais ou não, se mostra necessária (BRASIL, 2006).

Destarte, deve-se assumir o seu papel e se envolver com a responsabilidade de reverter as condições destas famílias, modificando-se a postura ainda frequente de se passar o problema adiante (AYRES; CARDOSO; PEREIRA, 2009). Para Souza e Carvalho (2007) é necessária uma comunicação mais efetiva entre estas instituições os conselhos tutelares, o poder judiciário e o ministério público, evitando-se processos tão questionados como os de destituição do poder familiar, os quais encerram a vinculação afetiva entre essas famílias e a sua prole, sem antes ter havido suficiente articulação entre as esferas acima citadas.

Visando modificar a cultura de institucionalização e a morosidade que envolve os processos que dizem respeito ao "Direito à Convivência Familiar", a Lei 12.010 (BRASIL, 2009b) realizou alterações no estatuto. Baseado no plano de promoção (BRASIL, 2006), o acolhimento deixou de ser restrito à modalidade institucional, reconhecendo-se e incentivando-se o acolhimento familiar e os programas de famílias de apoio. No entanto, a mudança mais revolucionária refere-se à periodicidade e a revisão desta medida, exigindo-se avaliação e atenção contínua às crianças e adolescentes acolhidos em instituição, dando preferência à manutenção ou à reintegração destes à sua família (BITTENCOURT, 2009).

Para a autora, as alterações introduzidas pela referida lei trouxeram maior responsabilidade aos profissionais da rede de proteção, ao município e às instituições de acolhimento, reforçando a importância da intersecção entre estes profissionais, as equipes técnicas e os operadores do Direito. Neste sentido, considerando que a execução do acolhimento institucional exige a abertura e o acompanhamento de cada criança, adolescente e sua família através de procedimentos jurídicos, mostra-se relevante identificar e analisar os fatores que, sob a ótica do poder judiciário, levam à aplicação desta medida ou a retomada da convivência familiar, por meio da análise das informações dos cadastros de crianças e adolescentes em acolhimento institucional.

\section{Objetivo}

O estudo buscou analisar as informações contidas nos cadastros de crianças e adolescentes em acolhimento institucional, identificando quais aspectos relacionados à dinâmica familiar, sob a ótica do poder judiciário, contribuíram para a aplicação da medida protetiva de acolhimento e/ou o desacolhimento institucional.

\section{Método}

Para a identificação dos aspectos relacionados ao propósito deste estudo foi utilizada a técnica de análise documental. Esta técnica se dirige a materiais que ainda não receberam um tratamento analítico e permite organizar informações que se encontram dispersas, conferindo-lhe uma nova importância como fonte de consulta. Por documento, entende-se qualquer registro que possa ser usado como fonte de informação, por meio de investigação, que engloba: observação crítica, leitura, reflexão ou crítica (PRODANOV; FREITAS, 2013).

Para Sá-Silva, Almeida e Guindani (2009), o uso de documentos em pesquisa deve ser apreciado e valorizado, pois a riqueza de informações que deles se pode extrair e resgatar justifica o seu uso em várias áreas das ciências humanas e sociais, uma vez que a técnica possibilita ampliar o entendimento de objetos cuja compreensão necessita de contextualização histórica e sociocultural. Além disso, a análise documental favorece a observação do processo de maturação ou de evolução de indivíduos, grupos, conceitos, conhecimentos, comportamentos, mentalidades e práticas, entre outros.

Para análise destes documentos, o material de estudo foi submetido à técnica de análise de conteúdo, definida como uma técnica de tratamento de dados de pesquisa voltada para uma descrição objetiva e sistemática do conteúdo das mensagens (BARDIN, 1977). Esta técnica permite compreender as mensagens dos documentos, classificando-as em categorias que permitam compreender o significado das comunicações. Embora a técnica tenha suas origens na pesquisa quantitativa, busca a interpretação de materiais de caráter qualitativo (GOMES, 2012; MINAYO, 1998).

\section{Material}

O material utilizado para a análise foram as informações processuais contidas nos cadastros de crianças e adolescentes em situação de acolhimento institucional de uma Vara de Infância e da Juventude de uma comarca localizada no interior do estado de São Paulo. Foram analisados e posteriormente tabulados somente os dados oriundos do cadastro de informações deste juízo. Neste cadastro constam as principais informações sobre os processos de acolhimento e de execução de medida protetiva de crianças e adolescentes que tiveram sua situação reavaliada e sentenciada.

Para a referida análise, foram utilizadas apenas as informações processuais de crianças e adolescentes que estiveram acolhidas entre outubro de 2012 e setembro de 2013. Aqueles que foram acolhidos posteriormente ou já estavam acolhidos, mas até o início deste período haviam sido desacolhidos não fizeram parte do material analisado. Durante o período analisado algumas crianças e adolescentes permaneceram acolhidas, enquanto outras foram desacolhidas, deste modo os dados foram divididos em dois grupos distintos: "acolhidos" (informações processuais daqueles que se encontravam institucionalmente acolhidos até setembro de 2013) e "desacolhidos" (informações 
processuais daqueles que foram desacolhidos e retomaram a convivência familiar até setembro de 2013, seja ela com a família natural, extensa ou com família adotiva). ${ }^{4}$

Este cadastro oferece apenas as principais informações sobre os processos, contendo dados tais como resumos e transcrições parciais de: relatórios técnicos das equipes da instituição de acolhimento e da rede de apoio e proteção do município; laudos da equipe técnica do juízo (assistentes sociais e psicólogos judiciários) e as principais decisões e proposições oferecidas pelos operadores do direito (juiz de direito, promotor de justiça e defensores públicos).

Os dados sobre a evolução de determinada criança, adolescente e sua família podem estar presentes em distintos processos: acolhimento institucional, execução de medida protetiva de crianças e adolescentes e perda, suspensão ou restabelecimento de poder familiar. O cadastro reúne todas estas informações processuais e é organizado e atualizado pelos próprios funcionários do juízo, que têm a função de registrar e armazenar as principais informações dos autos processuais.

\section{Aspectos Éticos}

Por se tratar de um estudo envolvendo informações relativas a seres humanos, a pesquisa foi submetida à avaliação do Comitê de Ética em Pesquisa e posteriormente aprovada sob o CAAE $n^{\circ} 27353714.7 .0000 .5383$. Como não se trata de pesquisa de campo, não houve contato dos pesquisadores com as pessoas descritas ou citadas nas informações processuais. Neste sentido, a técnica de pesquisa documental utilizada se configurou em um método de coleta de dados que eliminou a eventualidade de qualquer influência (presença ou intervenção do pesquisador) do conjunto das interações, acontecimentos ou comportamentos pesquisados, anulando-se a possibilidade de reação do sujeito à operação de medida (SÁ-SILVA; ALMEIDA; GUINDANI, 2009).

Como se trata de informações pessoais e jurídicas e que, portanto permanecem em segredo de justiça, o magistrado do referido juízo só permitiu o acesso e a exploração destes dados, desde que fossem garantidos o sigilo e o anonimato dos envolvidos nestes processos. Deste modo, são apontados somente dados descritivos, preservando-se a identidade das pessoas citadas nos autos processuais, bem como da referida comarca.

\section{Procedimentos de coleta de dados}

A partir do acesso às informações do cadastro, os dados foram selecionados e classificados em categorias pré-definidas, criadas pelos próprios pesquisadores através da revisão da literatura sobre o tema e uma leitura flutuante deste banco dados. Foram analisadas as seguintes categorias: período de acolhimento; constituição familiar (número de irmãos, presença/ausência de genitor); ${ }^{4}$ A lei no 8.069 (BRASIL, 1990) define "família natural" como a comunidade formada pelos pais ou qualquer deles e seus descendentes, enquanto que "família extensa ou ampliada" é considerada aquela que se estende para além da unidade pais e filhos ou da unidade do casal, formada por parentes próximos com os quais a criança ou adolescente convive e mantêm vínculos de afinidade e afetividade (Art. 25). Já a família adotiva é àquela que por meio de procedimento jurídico, foi atribuída à criança ou ao adolescente a condição de filho, com os mesmos direitos e deveres (Art. 41). informações sobre o vínculo com a família de origem e extensa; motivos que ensejaram o acolhimento; decisão judicial; conclusões dos laudos técnicos; informações oferecidas pela rede apoio, como por exemplo, os tipos de encaminhamento pelos quais a criança, adolescente ou sua família foi direcionada.

As responsáveis pela coleta e classificação eram todas estudantes do último ano do curso de Psicologia, elas se dividiram e se alternaram tomando o cuidado para que cada seleção do conjunto de informações relativas a uma determinada criança ou adolescente fosse realizada por no mínimo duas discentes, em dois momentos distintos, favorecendo assim a revisão da coleta de dados. Surgiram divergências ou dúvidas sobre qual categoria determinada informação deveria ser direcionada em apenas $13,5 \%$ dos registros. Nestes casos, as informações eram discutidas em conjunto com todas as pesquisadoras e o orientador deste estudo, professor e psicólogo judiciário com experiência em atividades ligadas a este tema.

\section{Análise de dados}

Após o levantamento inicial, os dados foram quantificados e analisados, classificando-se as crianças e adolescentes de acordo com: 1) condição em que se encontravam (acolhidos ou desacolhidos) e 2) o grupo familiar ao qual pertenciam. Como as informações do cadastro eram separadas por criança/adolescente, foram considerados do mesmo grupo familiar os indivíduos filhos da mesma genitora. O nome da genitora, portanto constituiu-se como a variável determinante para esta classificação. Insta salientar que sujeitos pertencentes a um mesmo grupo familiar nem sempre se encontravam na mesma condição, isso ocorreu em situações peculiares em que uma determinada criança ou adolescente permanecia acolhida enquanto seu grupo de irmãos havia sido desacolhido, estes casos foram destacados e analisados separadamente, sendo denominados de grupo "misto".

Estas peculiaridades geralmente ocorrem quando um grupo de irmãos é acolhido em diferentes momentos, trata-se de situações nas quais durante a execução do processo de acolhimento de uma determinada criança, sua genitora engravidou e, posteriormente se observou a necessidade de também acolher o irmão dela. Além disso, há situações em que um mesmo grupo de irmãos possui família extensa distinta, geralmente de origem paterna, o que pode definir um destino diferente para cada uma dessas crianças ou adolescentes.

Para a análise dos dados descritivos foi utilizada a técnica de análise de conteúdo, definida como uma avaliação sistemática de sinais de comunicação, aos quais se atribui valores numéricos de acordo com as regras de mensuração e validação que envolve métodos estatísticos (BARDIN, 1977; MINAYO, 1998). Nesse sentido, buscou-se realizar inferências sobre o significado dos textos analisados, realizando-se assim uma análise descritiva para cada grupo estudado.

A comparação dos dados entre os grupos (acolhidos e desacolhidos) foi calculada através: do Teste $t$ (Student); Teste de Mann-Whitney e Teste $\mathrm{x}^{2}$ (Qui-quadrado) utili- 
zando-se o programa STATISTICA (v. 12' 2013 edition); foi considerado o valor de significância $\mathrm{p}<0,05$ e $\mathrm{p}<0,01$. As categorias que a análise de conteúdo possibilitou encontrar nas mais variadas informações processuais, devido ao volume de dados, serão descritas na seção de resultados.

\section{Resultados e Discussão}

\section{Dados gerais}

A consulta realizada junto ao cadastro contabilizou um total de 89 registros de crianças e adolescentes oriundos de 45 (quarenta e cinco) famílias. O grupo "acolhidos" foi composto por 50 (cinquenta) indivíduos, oriundos de 26 (vinte e seis) famílias distintas e abrangeu mais da metade $(56,2 \%)$ da amostra. Já o grupo "desacolhidos" (29,2\%) foi formado por 26 (vinte e seis) indivíduos, oriundos de 18 (dezoito) famílias distintas. Apenas 14,6 \%: 8 (oito) crianças e 5 (cinco) adolescentes oriundos de 4 (quatro) famílias diferentes possuíam condição "mista", ou seja, parte dos irmãos foram desacolhidos, enquanto os demais ainda permaneceram acolhidos durante o período analisado (Tabela 1).

Tabela 1 - Frequência de crianças e adolescentes segundo o grupo o qual pertencem

\begin{tabular}{l|c|c|c} 
Grupo & Crianças & Adolescentes & Total \\
\hline Acolhidos & 42 & 8 & $\mathbf{5 0}(\mathbf{5 6 , 2} \%)$ \\
Desacolhidos & 21 & 5 & $\mathbf{2 6}(\mathbf{2 9 , 2} \%)$ \\
Misto & 8 & 5 & $\mathbf{1 3}(\mathbf{1 4 , 6 \% )}$ \\
Total & $\mathbf{7 1}$ & $\mathbf{1 8}$ & $\mathbf{8 9}$ \\
\hline
\end{tabular}

Fonte: produzida pelos autores

A maioria $(79,8 \%)$ é composta por indivíduos com até 12 (doze) anos incompletos (crianças); esta predominância de crianças sobre a de adolescentes também é observada em outros dois levantamentos nacionais a respeito do tema. Tanto o primeiro, conduzido por Fávero, Vitale e Baptista (2008), quanto o segundo desenvolvido pelo Ministério do Desenvolvimento Social em parceria com a Fiocruz (BRASIL, 2012) revelam que a maior parte desta população é composta por crianças. A comparação dos dois maiores grupos (acolhidos e desacolhidos) não aponta diferenças estatisticamente significativas com relação às variáveis: "média de idade" e "tempo médio de acolhimento".

No entanto, ao se analisar estas variáveis entre os indivíduos que formam o grupo "acolhidos", verifica-se diferenças estatisticamente significativas. Entre os "acolhidos", a maioria $(71,4 \%)$ possui a "situação jurídica provisória" (os genitores não foram destituídos do poder familiar e os esforços para reintegrá-los à família natural, extensa ou ampliada ainda não foram totalmente esgotados). Ao compará-los, observa-se que tanto a média de idade (6,4 anos) quanto o tempo médio de acolhimento (1,1 anos) deles é significativamente menor (Teste $U$ de Mann-Whitney, $\mathrm{p}<0,01)$ se comparado àqueles que possuem a "situação jurídica definida" (10,8 anos para média de idade e 3,4 anos para tempo médio de acolhimento).

Àqueles com situação jurídica definida (quando seus genitores já foram destituídos do poder familiar e todos os esforços para reintegrá-los à família de origem, extensa ou ampliada já foram esgotados) só poderão ter garantido o direito à convivência familiar através da adoção.
A análise dos dados, entretanto indica que a chance de se efetivar essas garantias se mostra reservada, uma que vez que as informações do CNJ (Conselho Nacional de Justiça $)^{5}$ apontam que o número de pessoas habilitadas no CNA (Cadastro Nacional de Adoção) diminui conforme a idade da criança ou adolescente aumenta, pois a maioria $(65,2 \%)$ dos inscritos almeja crianças com idade entre 0 (zero) e 4 (quatro) anos.

Neste sentido, considerando que a média de idade é superior e, portanto contrasta com o desejo da maioria dos pretendentes à adoção, é possível que o tempo médio de acolhimento se torne, ao longo dos anos, cada vez maior. Contraste semelhante também se observa ao analisar o número de crianças e adolescentes desejadas pelos pretendentes à adoção (CNA), onde a maioria $(65,4 \%)$ dos inscritos almeja adotar somente uma criança, enquanto que os indivíduos do grupo "acolhidos", em sua maioria $(60,9 \%){ }^{6}$ possuem irmãos.

Ainda em relação a esta variável, a análise dos resultados aponta que entre os indivíduos do grupo "acolhidos" é significativamente maior $\left(\mathrm{x}^{2}=6,12, \mathrm{p}<0,05\right)$ o número daqueles que possuem irmãos, se comparado com o grupo desacolhidos, onde a maioria $(77,8 \%)$ é composta somente por uma criança. Embora diversos fatores possam contribuir para a reintegração familiar, este estudo, em conjunto com os dados do CNJ, indica que crianças e adolescentes que possuem irmãos apresentam chance menor de voltar a conviver em família (natural, extensa/ampliada ou adotiva) se comparados àqueles que não possuem irmãos.

Já entre àqueles que retomaram a convivência familiar (desacolhidos), a maioria (51,5\%) retornou à família natural, enquanto um terço $(33,3 \%)$ ficou sob a guarda e responsabilidade da família extensa. Apenas 9,1\% destes indivíduos foram encaminhados para adoção, enquanto $6,1 \%$ tiveram um desfecho diferente. Nestes casos, uma criança ficou com a guarda do genitor dos irmãos unilaterais, enquanto em outra família, uma criança ficou sob a responsabilidade da ex-companheira de seu genitor.

Estes últimos casos demonstram que a ideia de família é muito mais ampla e não se restringe apenas à relação consanguínea, configurando-se no que Paulo (2009) define como: uma relação socioafetiva. Para Fonseca (2002) a compreensão da vida familiar no Brasil contemporâneo exige o esforço para considerar, além da norma hegemônica, também essas dinâmicas alternativas, práticas que possuem densidade histórica.

No entanto, os resultados acima apontam um aspecto ainda mais relevante: a família (natural ou extensa) é o principal destino de crianças e adolescentes que deixam o acolhimento. A adoção, conforme preceitua o estatuto, deve ser pensada apenas quando todas as estratégias e intervenções junto à família se mostrarem esgotadas (FONSECA, 1995). Além disso, mesmo nestas situações não

${ }^{5}$ Conselho Nacional de Justiça - Cadastro Nacional de Adoção, disponível em: https://www.cnj.jus.br/. Acesso em: 27 outubro 2017.

${ }^{6}$ Este valor é bem próximo à porcentagem atual de crianças e adolescentes acolhidos no território nacional $(59,35 \%)$ que possuem irmãos. Fonte: Cadastro Nacional de Adoção, disponível em: https://www.cnj.jus.br/. Acesso em: 27 outubro 2017. 
se deve pensá-la como um recurso efetivo, uma vez que a realidade da maioria desses indivíduos acolhidos diverge do perfil daqueles que pretendem adotar.

Destarte, a família, por vezes considerada a principal responsável pela situação de risco em que se encontram essas crianças e adolescentes, deve ser encarada como o melhor e o mais viável recurso para o enfrentamento do problema (VONS; MIRANDA, 2009). Além disso, se o tamanho da prole pode dificultar a reintegração familiar é provável que este aspecto também a torne ainda mais vulnerável, exigindo-se, portanto que essas famílias recebam apoio e orientação de forma mais intensa da rede de proteção e das políticas públicas (PITTA; FONTOURA, 2009).

\section{Contato das crianças com a família}

Com relação à "família natural”, em aproximadamente um terço dos registros de ambos os grupos não havia informações sobre o contato entre estas famílias e os filhos durante o período de acolhimento. Embora os cálculos não apontem diferenças significativas entre os grupos $\left(\mathrm{x}^{2}=3,35, \mathrm{p}=0,06\right)$, a análise qualitativa destas informações revela importante contraste entre eles: enquanto em "acolhidos" a maioria (43,5\%) se mostrou irregular ou ausente; somente em $16,7 \%$ das famílias do grupo "desacolhidos" se observou esta situação, pois metade (50\%) delas manteve regularidade no contato com a prole.

Quanto à "família extensa ou ampliada", diferenças estatisticamente significativas podem ser observadas entre os grupos. No grupo "acolhidos" a falta de familiares que possam assumir a responsabilidade é significativamente maior $\left(x^{2}=4,04, p<0,05\right)$, enquanto que no grupo "desacolhidos" é significativamente maior $\left(x^{2}=7,67\right.$, $\mathrm{p}<0,01)$ o número de famílias que estabeleceram contato durante o período de acolhimento e manifestaram interesse em assumir a guarda ou a responsabilidade.

Estes dados sugerem que a regularidade e o interesse da família (extensa ou natural) no contato com as crianças e adolescentes, durante o período de acolhimento, estão entre os principais motivos que levam o poder judiciário a decidir pelo desacolhimento e a retomada da convivência familiar. No entanto, outros estudos, realizados junto aos dirigentes destas instituições e os familiares que possuem filhos acolhidos, indicam que nem sempre eles atribuem a retomada da convivência familiar a estes aspectos.

Diferente do presente estudo, que concentrou a análise nas informações processuais, tais pesquisas foram realizadas junto às instituições de acolhimento e/ou responsáveis pelas crianças e adolescentes acolhidas. No levantamento realizado pelo IPEA (INSTITUTO DE PESQUISA ECONÔMICA APLICADA, 2005) junto aos dirigentes das instituições, a falta de condições socioeconômicas destas famílias foi citada, entre outros, como o principal motivo $(35,5 \%)$ que impede a reintegração familiar, segundo os entrevistados.

Fávero, Vitale e Baptista (2008) no estudo realizado junto aos familiares, observaram que mais da metade (62\%) dos entrevistados consideram que para reintegrar os filhos seria necessário o poder judiciário acreditar que eles tem condições (moradia, emprego e renda) para mantê-los.
É importante destacar que o principal motivo apontado nestes estudos, a falta de condições socioeconômicas, não justifica a aplicação de medida protetiva de acolhimento institucional, pois nos casos de carência material o estatuto (Lei $\left.{ }^{\circ} 8.069 / 1990\right)$ estabelece a obrigatoriedade de inclusão da família em programas oficiais de auxílio.

Não se trata, contudo, de desconsiderar que a falta de condições socioeconômicas contribui para a vulnerabilidade social em que estas famílias se encontram, pois tais condições podem estar articuladas a outros fatores determinantes da violação de direitos, o que pode ter justificado a necessidade de acolhimento institucional (SILVA; AQUINO, 2005). O contraste entre os elementos pelos quais o poder judiciário se baseia para definir a possibilidade de reintegração familiar e a representação que estes grupos fazem sobre este tema revela que, apesar dos avanços na legislação, ainda se preserva a ideia de que o Estado, através do poder judiciário, tem como função exercer o controle social das famílias, tutelando crianças e adolescentes oriundos das camadas menos favorecidas (CIARALLO; ALMEIDA, 2009).

Algumas das famílias que tiveram seus filhos acolhidos podem se sentir excluídas e penalizadas, concluindo que não possuem capacidade ou que a sua situação de vulnerabilidade jamais lhes permitirá reassumir as suas funções, levando-as à desistência (SILVA, 2009). No entanto, a leitura dos dados demonstra que é durante o acolhimento que a família, natural ou extensa, se torna ainda mais importante, devendo-se desconstruir as crenças e os rótulos que os levam a se sentirem incapazes, excluídas ou até mesmo perseguidas (NASCIMENTO, 2012).

Os resultados apontam que mesmo quando as políticas de promoção e de proteção não se mostram suficientes para garantir a preservação de direitos, como a convivência familiar, os esforços junto a essas famílias continuam sendo fundamentais e ainda mais necessários. Os profissionais que compõem o sistema de garantia de direitos são figuras importantes neste processo, pois é por meio deles que as famílias poderão perceber a mudança de paradigma, de um Estado que vigiava e tutelava a sua prole, para o novo panorama, onde a família, com auxílio de políticas públicas, é quem deve assumir o protagonismo e desenvolver autonomia (NASCIMENTO; COUTINHO; SÁ, 2010).

\section{Aspectos que ensejaram o acolhimento institucional}

A análise de conteúdo do cadastro possibilitou identificar 20 (vinte) categorias distintas sobre os motivos que levaram crianças e adolescentes a serem submetidos à medida de acolhimento institucional (Tabela 2). O número de motivos que acarretou na aplicação da medida variou entre 3 (três) e 5 (cinco) em ambos os grupos, não havendo, portanto diferença estatisticamente significativa. De acordo com Fávero, Vitale e Baptista (2008), raramente existe um único motivo que acarrete o acolhimento de uma criança e/ou adolescente, pois uma gama de fatores geralmente está relacionada à aplicação da medida.

Fractal, Rev. Psicol., v. 30 - n. 2, p. 223-233, 2018 
Tabela 2 - Motivos que ensejaram o acolhimento institucional

\begin{tabular}{|c|c|c|c|c|c|}
\hline & Motivos & Acolhidos & Desacolhidos & Total & $(\%)$ \\
\hline \multirow{6}{*}{ Negligência: } & do exercício da função parental & 18 & 10 & 28 & $68,3 \%$ \\
\hline & dos cuidados básicos & $12^{*}$ & 3 & 15 & $36,6 \%$ \\
\hline & afetiva (é localizado, mas não dá a atenção necessária) & 4 & 3 & 7 & $17,1 \%$ \\
\hline & abandono de lar ou sem paradeiro definido & 1 & $5^{*}$ & 6 & $14,6 \%$ \\
\hline & em relação à própria saúde & $5^{*}$ & 0 & 5 & $12,2 \%$ \\
\hline & em relação à gestação & 1 & 0 & 1 & $2,4 \%$ \\
\hline \multirow{4}{*}{ Violência: } & entre os genitores & 4 & 2 & 6 & $14,6 \%$ \\
\hline & Física & 6 & 4 & 10 & $24,4 \%$ \\
\hline & Psicológica & 1 & 2 & 3 & $7,3 \%$ \\
\hline & sexual (suspeita, exploração, etc...) & 3 & 4 & 7 & $17,1 \%$ \\
\hline \multirow{2}{*}{ Saúde: } & diagnóstico e necessidade de internação psiquiátrica & 0 & 1 & $\mathbf{1}$ & $2,4 \%$ \\
\hline & problemas de saúde que impedem o exercício parental & 0 & 2 & 2 & $4,9 \%$ \\
\hline \multicolumn{2}{|c|}{ Exploração do trabalho infantil e/ou exposição à mendicância } & 0 & 2 & 2 & $4,9 \%$ \\
\hline \multicolumn{2}{|c|}{ Uso de álcool e/ou drogas } & $23^{*}$ & 14 & 37 & $90,2 \%$ \\
\hline \multicolumn{2}{|c|}{ Envolvimento com tráfico de drogas } & 0 & 2 & 2 & $4,9 \%$ \\
\hline \multicolumn{2}{|c|}{ Estar cumprindo pena restritiva de liberdade } & 8 & 5 & 13 & $31,7 \%$ \\
\hline \multicolumn{2}{|c|}{ Envolvimento com prostituição } & 2 & 3 & 5 & $12,2 \%$ \\
\hline \multicolumn{2}{|c|}{ Lar em inadequadas condições de habitação } & 9 & 4 & 13 & $31,7 \%$ \\
\hline \multicolumn{2}{|c|}{ Falta de moradia e/ou vivência em situação de rua } & 4 & 0 & 4 & $9,8 \%$ \\
\hline \multicolumn{2}{|l|}{ Orfandade } & 4 & 0 & 4 & $9,8 \%$ \\
\hline
\end{tabular}

$\left({ }^{*} \mathrm{p}<0,05\right)$ Fonte: produzida pelos autores

Os motivos que desencadearam o acolhimento institucional com maior incidência, em ambos os grupos, são: "uso de álcool e/ou drogas" pelos responsáveis (90,2\%); seguido de "negligência da função parental" (68,3\%), que se refere à adequada participação dos pais na educação ${ }^{7}$ oferecida aos filhos; "negligência dos cuidados básicos" (36,6\%), referente à falta de cuidados relativos à higiene e alimentação, entre outras funções básicas; "lar em inadequadas condições de habitação" (31,7\%) e "restrição de liberdade dos genitores" que cumpriam pena restritiva de direitos $(31,7 \%)$.

Comparando-se os grupos, observa-se frequência significativamente maior em "acolhidos" para os seguintes motivos: "negligência dos cuidados básicos" $\left(x^{2}=5,49, p\right.$ $<0,05)$; "uso de álcool e/ou drogas" pelos responsáveis $\left(\mathrm{x}^{2}=5,66, \mathrm{p}<0,05\right)$ e "negligência destes em relação à própria saúde" $\left(\mathrm{x}^{2}=4,46, \mathrm{p}<0,05\right)$. Interessante observar que estes motivos estão entrelaçados, uma vez que a "negligência em relação à própria saúde" mais observada nos registros foi a resistência dos responsáveis em aceitar tratamento para o uso problemático destas substâncias.

$\mathrm{O}$ único motivo significativamente maior $\left(\mathrm{x}^{2}=4,44\right.$, $\mathrm{p}<0,05)$ em "desacolhidos" é a negligência do tipo "abandono de lar sem paradeiro definido". Nestes casos pode ser que diante a ausência dos pais, ocorra, talvez, maior mobilização da família extensa em se aproximar e se responsabilizar pelas crianças e adolescentes em situação de abandono. De modo geral, embora não se observe um motivo que isoladamente justifique a medida de acolhimento, os dados sugerem que o "uso de álcool e drogas" muito provavelmente contribui ou está associado aos demais motivos, como: negligência, violência ou detenção dos responsáveis.

\footnotetext{
Nesta categoria foram incluídos os casos em que os responsáveis foram acusados de não responder às demandas apontadas pelas escolas ou, permitir a permanência dos filhos pelas ruas sem a supervisão adequada.
}

Grande parte da literatura nacional destaca as consequências dessas práticas no âmbito familiar quando os usuários são os filhos, em sua maioria adolescentes e jovens adultos. No entanto, os resultados indicam que o uso dessas substâncias pelos responsáveis pode gerar consequências ainda mais devastadoras, acarretando o rompimento do vínculo e da convivência familiar. No levantamento realizado pela Fiocruz (BRASIL, 2012), observa-se que o uso de álcool e/ou drogas pelos pais se configura no segundo principal motivo de acolhimento.

A "negligência dos pais ou responsáveis", seja em relação à "função parental" ou "dos cuidados básicos", também foi um dos mais frequentes motivos analisados. No levantamento da Fiocruz (BRASIL, 2012) a negligência é o motivo que mais está associado às justificativas que ensejam o acolhimento, enquanto que no estudo realizado por Fávero, Vitale e Baptista (2008) os familiares (família extensa) atribuem a negligência dos pais como o segundo principal motivo para o acolhimento de crianças e adolescentes.

Ao observar que na ordem dos motivos surge "lar em inadequadas condições de habitação", pondera-se que a negligência dos pais não se restringe somente à prole, sugerindo que os responsáveis, por motivos que não foram possíveis explorar, geralmente se tornam negligentes em diversas áreas de sua vida. Os dados analisados, assim como os estudos citados anteriormente indicam que essas famílias, na grande maioria, vivem em condição de vulnerabilidade social. Ainda que este aspecto, por si só, não justifique o acolhimento, autores como Pitta e Fontoura (2009) e Bittencourt (2009) ressaltam que a pobreza pode estar relacionada à causa remota da disfuncionalidade emocional que cerca estas famílias. 
Pela frequência apresentada, vale destacar o fato de que em quase um terço destas famílias os "genitores estavam cumprindo pena restritiva de liberdade". Embora não seja o mais frequente, este motivo também foi encontrado no estudo realizado pelo IPEA (2005) e no levantamento da Fiocruz (BRASIL, 2012). Estes dados indicam a dificuldade destes pais em se engajar no mercado de trabalho formal e a proximidade destas famílias com a violência e a criminalidade. Daí a importância de políticas públicas específicas para garantir não só a convivência familiar de crianças e adolescentes como também promover o fortalecimento e a proteção destas famílias (BRASIL, 2006, 2009a).

A violência contra crianças e adolescentes também foi identificada e ainda que isoladamente nenhuma de suas formas esteja entre os cinco principais motivos, deve-se destacar que em aproximadamente um quarto dessas famílias $(24,4 \%)$ a suspeita de "violência física" esteve presente, enquanto em quase um quinto destes núcleos familiares $(17,1 \%)$ crianças e adolescentes possivelmente foram submetidos à "violência sexual", seja ela na forma de abuso ou de exploração.

Além disso, formas de violência talvez 'menos visíveis' também foram observadas, como no caso de: "violência psicológica" (7,3\%); "abandono do lar" (14,6\%) e "negligência afetiva" dos pais $(17,1 \%)$, os quais mesmo localizados não ofereciam a atenção necessária aos filhos. Silva e Aquino (2005) afirmam que na maioria dos casos os acolhimentos ocorrem visando proteger as crianças e os adolescentes daqueles que deveriam zelar por eles, ou seja, seus responsáveis. Com relação a este aspecto, os resultados corroboram com a afirmação, sendo possível observar que os pais (família natural) foram os perpetradores da violência física, sexual ou psicológica na maioria (70\%) dos casos em que estas suspeitas foram apontadas.

$\mathrm{O}$ fato de que nenhum motivo, isoladamente, possa ser apontado como a causa dos acolhimentos, haja vista que na maioria dos registros foram encontrados mais de um, indica que além de entrelaçados, os aspectos aqui analisados não devem ser entendidos como identificadores ou rotulares destas famílias. Pelo contrário, a negligência que muitas vezes se observa em relação à prole parece ser consequência de um conjunto de vulnerabilidades em que esses pais e responsáveis se encontram (NASCIMENTO, 2012).

Além disso, não é difícil imaginar que frente a esse cenário de fragilidades e vulnerabilidades em que se encontram, o uso de álcool e drogas possa ser entendido como um recurso, ainda que disfuncional e desorganizador, para lidar com a difícil realidade em que essas famílias vivem (CÂMARA, 2012). Destarte, sob o paradigma atual, os aspectos aqui analisados devem ser úteis para identificar os pontos que demandam maior proteção e prevenção, pois se utilizados como formas de classificar estes indivíduos, corre-se o risco de se regredir ao modelo anterior, no qual a vulnerabilidade da família justificava a intervenção do Estado por meio de punição, ao invés de se garantir a sua proteção (NASCIMENTO, 2012).
Os resultados demonstram a importância de se compreender os fatores que acarretam o acolhimento institucional não como forma de identificar ou rotular essas famílias, mas sim para evidenciar a importância de se investir em estratégias que garantam a sua proteção e consequentemente a convivência familiar. No entanto, devido as suas peculiaridades não permite realizar inferências ou considerações mais abrangentes, uma vez que as informações processuais submetidas à análise referem-se somente aos dados de uma única comarca, analisados e sentenciados durante um curto período de tempo.

\section{Considerações finais}

O estudo permitiu analisar as informações processuais relacionadas ao acolhimento institucional de crianças e adolescentes, bem como identificar quais aspectos relacionados à dinâmica familiar, sob a ótica do poder judiciário, contribuíram para a aplicação da medida protetiva de acolhimento e/ou o desacolhimento institucional. A alta incidência do uso de álcool e/ou drogas pelos responsáveis como um dos motivos que demanda a aplicação de medidas protetivas coaduna com outros levantamentos, sugerindo que tais práticas não só colaboram para o acolhimento institucional como também dificultam a reintegração familiar.

Contudo, nenhum motivo pode ser isoladamente considerado como a causa principal do acolhimento institucional, haja vista que os registros indicaram mais de um motivo como justificativa para a medida. Fatores tais como o uso de álcool e/ou drogas, a negligência dos responsáveis em relação aos filhos, a si próprios e aos cuidados do lar, bem como a proximidade dessas famílias com a violência e a criminalidade sugerem estar interligados.

Nesse sentido, é importante que estes aspectos sejam interpretados como indicadores da vulnerabilidade em que essas famílias se encontram, bem como da necessidade de investimento em políticas públicas e programas sociais. Utilizar esses fatores para identificar e rotular essas famílias apenas contribui para intensificar o processo de exclusão e justificar intervenções que desrespeitam as legislações atuais que, sob o novo paradigma, visam à garantia de direitos fundamentais a crianças e adolescentes, entre eles: a convivência familiar.

No que se refere ao período de acolhimento, os achados indicam que a regularidade e o interesse da família se constituem em um dos principais aspectos que favoreceram a reintegração familiar. Compreende-se que durante a aplicação da medida o contato dos pais, responsáveis e demais familiares com as equipes técnicas das instituições de acolhimento e outros equipamentos e serviços que compõem a rede de apoio e proteção à infância se mostram fundamentais, podendo os profissionais intervir e oferecer orientações para que as famílias possam reassumir as suas funções.

No entanto, quando a aproximação das equipes técnicas com as famílias não se torna possível ou as intervenções não são efetivas, dada a precariedade e disfuncionalidade em que muitas dessas famílias se encontram, somente a adoção pode garantir o direito à 
convivência familiar. Nessas situações tais garantias se mostram reservadas, haja vista o contraste entre o perfil dessas crianças e adolescentes e àquele almejado pelas pessoas interessadas na adoção, principalmente no que se refere à idade e o número de irmãos.

Neste contexto, a probabilidade desses indivíduos em permanecerem acolhidos se mostra cada vez maior, o que indica a necessidade de se investir na prevenção e promoção dessas famílias. Políticas públicas de saúde, assistência e desenvolvimento social se mostram fundamentais. A Política Nacional de Assistência Social apresenta as bases e referências necessárias para a sua implantação, devendo as ações desenvolvidas centrarem-se na família, fortalecendo e resgatando os vínculos familiares e comunitários (BRASIL, 2009a).

Já em relação à saúde, deve-se destacar as políticas voltadas para a prevenção do uso de álcool e drogas, tornando-se importante deixar de se enfatizar este tema apenas pelo prisma da justiça e da repressão, discutindo-o principalmente como um problema de saúde (BRASIL, 2011). Além disso, mostra necessário interligar os serviços e equipamentos que compõem a rede de proteção, fortalecendo a comunicação entre as unidades. Tal estratégia poderia evitar o acolhimento de crianças e adolescentes e, nos casos em que a aplicação da medida for necessária, garantir uma cobertura mais ampla.

Por fim, a comparação dos dados entre crianças e adolescentes que se encontram acolhidos com aqueles que foram desacolhidos evidencia um aspecto importante: ainda que as dificuldades encontradas nessas famílias muitas vezes justifiquem a aplicação da medida pelo poder judiciário, é também por meio dessas famílias ou da família extensa, que o poder judiciário consegue, na maioria dos casos, garantir o direito à convivência familiar. Daí a importância do trabalho conjunto entre os profissionais das equipes técnicas e os demais profissionais que compõem a rede de apoio e proteção.

Levantamentos mais abrangentes e pesquisas que enfoquem principalmente as dificuldades ou resistências destes pais e responsáveis em se engajar nos encaminhamentos realizados pelas equipes técnicas poderão ampliar a compreensão do tema, assim como preencher a lacuna existente na literatura nacional. Além disso, estudos semelhantes que possam analisar as informações processuais em períodos mais longos e em outras comarcas (estudos multicêntricos) se mostram importantes, pois permitiriam avaliar as considerações aqui levantadas em uma dimensão mais ampla.

\section{Referências}

AYRES, L. S. M.; CARDOSO, A. P.; PEREIRA, L. C. O abrigamento e as redes de proteção para a infância e a juventude. Fractal: Revista de Psicologia. Rio de Janeiro, v. 21, n. 2, p. 125-136, jan./abr. 2009. Disponível em: http://www.scielo.br/ pdf/fractal/v21n1/10.pdf. Acesso em: 29 out. 2017.

BARDIN, L. Análise de Conteúdo. Lisboa: Edições 70, 1977.

Fractal, Rev. Psicol., v. 30 - n. 2, p. 223-233, 2018
BITTENCOURT, S. R. O direito à convivência familiar e o laudo da equipe técnica: considerações essenciais. In: PAULO, B. M. (Coord.) Psicologia na Prática Jurídica: a criança em foco. Rio de Janeiro: Impetus, 2009. p. 49-60.

BRASIL. Presidência da República. Casa Civil. Subchefia para Assuntos Jurídicos. Decreto $n^{\circ} 17.943-A$ de 12 de outubro de 1927. Consolida as leis de assistencia e protecção a menores. Código de Menores. 1927. Disponível em: http://www.planalto. gov.br/ccivil_03/decreto/1910-1929/d17943a.htm. Acesso em: 13 mar. 2015

BRASIL. Presidência da República. Casa Civil. Subchefia para Assuntos Jurídicos. Lei $n^{\circ}$ 6.697, de 10 de outubro de 1979. Institui o Código de Menores. 1979. Disponível em: http:// www.planalto.gov.br/ccivil 03/leis/1970-1979/16697.htm. Acesso em: 15 mar. 2015.

BRASIL. Presidência da República. Casa Civil. Subchefia para Assuntos Jurídicos. Constituição da República Federativa do Brasil de 1988. Disponível em: http://www.planalto.gov.br/ ccivil 03/constituicao/constituicao.htm. Acesso em: 29 out. 2017.

BRASIL. Presidência da República. Casa Civil. Subchefia para Assuntos Jurídicos. Lei $n^{\circ}$ 8.069, de 13 de julho de 1990. Dispõe sobre o Estatuto da Criança e do Adolescente e dá outras providências. 1990. Disponível em: http://www.planalto.gov. br/ccivil 03/leis/L8069.htm. Acesso em: 29 out. 2017.

BRASIL. Presidência da República. Casa Civil. Subchefia para Assuntos Jurídicos. Lei $n^{\circ}$ 8.742, de 7 de dezembro de 1993. Lei Orgânica da Assistência Social. Dispõe sobre a organização da Assistência Social e dá outras providências. 1993. Disponível em: http://www.planalto.gov.br/ccivil 03/Leis/L8742.htm. Acesso em: 22 fev. 2015.

BRASIL. Ministério do Desenvolvimento Social e Combate à Fome. Política Nacional de Assistência - PNAS/2004 Norma Operacional Básica - NOB/SUAS. Brasília: MDS, 2005. Disponível em: http://www.mds.gov.br/webarquivos/ publicacao/assistencia_social/Normativas/PNAS2004.pdf. Acesso em: 13 mar. $201 \overline{5}$.

BRASIL. Presidência da República. Secretaria Especial dos Direitos Humanos. Ministério do Desenvolvimento Social e Combate à Fome. Plano Nacional de Promoção, Proteção e Defesa do Direito de Crianças e Adolescentes à Convivência Familiar e Comunitária. 2006. Disponível em: http://www.sdh. gov.br/assuntos/criancas-e-adolescentes/programas/pdf/planonacional-de-convivencia-familiar-e.pdf. Acesso em: 15 out. 2017.

BRASIL. Ministério do Desenvolvimento Social e Combate à Fome. Guia de Politicas e Programas do Ministério do Desenvolvimento Social e Combate à Fome. Brasília: MDS, 2008. Disponível em: http://www.mds.gov.br/webarquivos/ publicacao/assistencia social/Guia/GuiaPoliticasMDS.pdf. Acesso em: 12 ago. 2015.

BRASIL. Ministério do Desenvolvimento Social e Combate à Fome. Secretaria Nacional de Assistência Social. Sistema Único de Assistência Social-SUAS. 2009a. Disponível em: http://www.desenvolvimentosocial.sp.gov.br/portal.php/ assistencia sistema. Acesso em: 15 out. 2017. 
BRASIL. Presidência da República. Casa Civil. Subchefia para Assuntos Jurídicos. Lei $n^{\circ}$ 12.010, de 3 de agosto de 2009. Dispõe sobre adoção; altera as Leis n. ${ }^{\circ} 8.069$, de 13 de julho de 1990 - Estatuto da Criança e do Adolescente, 8.560, de 29 de dezembro de 1992; revoga dispositivos da Lei no 10.406, de 10 de janeiro de 2002 - Código Civil, e da Consolidação das Leis do Trabalho - CLT, aprovada pelo Decreto-Lei no 5.452, de $1^{\circ}$ de maio de 1943; e dá outras providências. 2009b. Disponível em: http://www.planalto.gov.br/ccivil_03/_ato2007-2010/2009/1ei/ 112010.htm. Acesso em: 29 out. 2017.

BRASIL. Presidência da República. Casa Civil. Subchefia para Assuntos Jurídicos. Emenda Constitucional $n^{\circ}$ 65, de 13 de julho de 2010. Altera a denominação do Capítulo VII do Título VIII da Constituição Federal e modifica o seu art. 227, para cuidar dos interesses da juventude. 2010. Disponível em: http:/ www.planalto.gov.br/ccivil_03/constituicao/emendas/emc/ emc65.htm. Acesso em: 12 out. 2017.

BRASIL. Ministério da Justiça. Secretaria Nacional de Políticas sobre Drogas. Legislação e Política Nacional Sobre Drogas. Brasília: Senad, 2011. Disponível em: http://www.justica. gov.br/central-de-conteudo/politicas-sobre-drogas/cartilhaspoliticas-sobre-drogas/2011legislacaopoliticaspublicas.pdf. Acesso em: 29 out. 2017.

BRASIL. Ministério do Desenvolvimento Social e Combate à Fome. Secretaria Nacional de Assistência Social. Fundação Oswaldo Cruz. Levantamento Nacional das Crianças e Adolescentes em Serviços de Acolhimento. Brasília: SNAS/ MDS; FIOCRUZ/CLAVES, 2012. Disponível em: https:// static1.squarespace.com/static/56b10ce8746fb97c2d267b79/t/ 56b4f6f38a65e204ee2647ab/1454700286830/levantamento nacional_das_criancas + e+adolescentes_em_servicos_de acolhimento.pdf. Acesso em: 29 out. 2017.

CÂMARA, G. O papel da droga para o sujeito no mal-estar da civilização atual. Cógito, Salvador, v. 13, p. 53-57. 2012. Disponível em: http://pepsic.bvsalud.org/pdf/cogito/v13/ v13a08.pdf. Acesso em: 20 out. 2017.

CIARALLO, C. R. C. A.; ALMEIDA, A. M. O. Conflito entre práticas e leis: a adolescência no processo judicial. Fractal: Revista de Psicologia, Niterói, v. 21, n. 3, p. 613-630. 2009. Disponível em: http://www.scielo.br/pdf/fractal/v21n3/14.pdf. Acesso em: 29 out. 2017.

CUNHA, C. C.; BOARINI, M. L. A infância sob a tutela do Estado: alguns apontamentos. Psicologia: Teoria e Prática, São Paulo, v. 12, n. 1, p. 208-224, 2010. Disponível em: http:// pepsic.bvsalud.org/pdf/ptp/v12n1/v12n1a17.pdf. Acesso em: 29 out. 2017.

FÁVERO, E. T.; VITALE, M. A. F.; BAPTISTA, M. V. Famílias de crianças e adolescentes abrigados: quem são, como vivem, o que pensam, o que desejam. São Paulo: Paulus, 2008.

FONSECA, C. Caminhos da adoção. São Paulo: Cortez, 1995.

FONSECA, C. Mãe é uma só? - Reflexões em torno de alguns casos brasileiros. Psicologia USP, São Paulo, v. 13, n. 2, p. 49-68, 2002. Disponível em: http://www.scielo.br/scielo. php? script $=$ sci_arttext\&pid=S0103-65642002000200005. Acesso em: 20 out. 2017.
GOMES, R. Análise e interpretação de dados de pesquisa qualitativa. In: MINAYO, M. C. S. (Org.). Pesquisa Social: teoria, método e criatividade. Rio de Janeiro: Vozes, 2012. p. 79-108.

INSTITUTO DE PESQUISA ECONÔMICA APLICADA. Levantamento Nacional de Abrigos para Crianças e Adolescentes da Rede de Serviços de Ação Continuada. 2005. Disponível em: http://www.mpsp.mp.br/portal/page/ portal/infanciahome c/acolhimento institucional/Doutrina abrigos/IPEA._Levantamento_Nacional_de_abrigos_para Criancas e Adolescentes da Rede SAC.pdf. Acesso em: 29 out. 2017.

MINAYO, M. C. S. O desafio do conhecimento: pesquisa qualitativa em saúde. São Paulo: Hucitec, 1998.

MIRANDA, G. L. de. Serviço de Acolhimento Institucional para Crianças e Adolescentes: feedback effects, inflexões e desafios atuais. Revista de Administração Pública, Rio de Janeiro, v. 51, n. 2, p. 201-218, mar. 2017. Cross ${ }^{\text {Ref }}$.

MOREIRA, J. S. S.; MIRANDA, V. R. Reinserção familiar: sim ou não? Diferentes facetas de uma longa e difícil história familiar. In: CARVALHO, M. C. N.; MIRANDA, V. R. (Org.) Psicologia Jurídica: Temas de Aplicação I. Curitiba: Juruá, 2007. p. 61-78.

MOREIRA, M. I. C. Os impasses entre acolhimento institucional e o direito à convivência familiar. Psicologia \& Sociedade, Belo Horizonte, v. 26, n. especial 2, p. 28-37, 2014. Cross ${ }^{\text {Ref. }}$

NASCIMENTO, M. L. Abrigo, pobreza e negligência: percursos de judicialização. Psicologia \& Sociedade, Belo Horizonte, v. 24, n. especial, p. 39-44. 2012. Disponível em: http://www.scielo.br/pdf/psoc/v24nspe/07.pdf. Acesso em: 20 out. 2017.

NASCIMENTO, M. L.; COUTINHO, A. P. C.; SÁ, D. A. Análises de produções escritas sobre abrigos para crianças e adolescentes. Pesquisas e Práticas Psicossociais, São João Del-Rei, v. 5, n. 1, p. 104-111. 2010. Disponível em: https:// ufsj.edu.br/portal2-repositorio/File/revistalapip/volume5 n1/ nascimento_et_al.pdf. Acesso em: 20 out. 2017.

PAULO, B. M. Família: uma relação socioafetiva. In: PAULO, B. M. (Coord.) Psicologia na Prática Jurídica: a criança em foco. Rio de Janeiro: Impetus, 2009. p. 27-38.

PITTA, D. S.; FONTOURA, T. O Direito da criança e do adolescente à convivência familiar: uma questão de políticas públicas? In: CARVALHO, M. C. N.; FONTOURA, T.; MIRANDA. V. R. (Org.) Psicologia Jurídica: Temas de Aplicação II. Curitiba: Juruá, 2009. p. 143-164.

PRODANOV, C. C.; FREITAS, E. C. de. Metodologia do Trabalho Científico: métodos e técnicas da pesquisa e do trabalho acadêmico. 2. ed. Novo Hamburgo, RS: Feevale, 2013.

RAMOS, P. A. Acolhimento institucional de crianças e suas consequências. In: PAULO, B. M. (Coord.) Psicologia na Prática Jurídica: a criança em foco. Rio de Janeiro: Impetus, 2009. p. 79-90. 
SÁ-SILVA, J. R.; ALMEIDA, C. D.; GUINDANI, J. F. Pesquisa documental: pistas teóricas e metodológicas. Revista Brasileira de História \& Ciências Sociais, São Leopoldo, v. 1, n. 1, p. 1-15, jul. 2009. Disponível em: https://www.rbhes.com/rbhes/ article/view/6/pdf. Acesso em: 29 jan. 2014.

SILVA, D. M. P. Psicologia Jurídica no Processo Civil Brasileiro: a interface da Psicologia com o Direito nas questões de família e infância. Rio de Janeiro: Forense, 2009.

SILVA, E. R. A.; AQUINO, L. M. C. Os abrigos para crianças e adolescentes e o direito à convivência familiar e comunitária. Brasília: IPEA, 2005. Disponível em: http://ipea.gov.br/ agencia/images/stories/PDFs/politicas_sociais/ENSAIO3 Enid11.pdf. Acesso em: 20 out. 2017.

SOUZA, M.; CARVALHO, M. C. N. Psicologia jurídica nos abrigos: uma análise sistêmica do Direito à convivência familiar. In: CARVALHO, M. C. N.; MIRANDA, V. R. (Org.). Psicologia Jurídica: Temas de Aplicação I. Curitiba: Juruá, 2007. p. 21-42.

VONS, D. K.; MIRANDA, V. R. Família, o melhor abrigo: da institucionalização à promoção e fortalecimento da família. In: CARVALHO, M. C. N.; FONTOURA, T.; MIRANDA. V. R. (Org.). Psicologia Jurídica: Temas de Aplicação II. Curitiba: Juruá, 2009. p. 189-201.

Recebido em: 13 de abril de 2015

Aceito em: 30 de outubro de 2017 